\title{
Allocation of Potentially Environmentally Hazardous Sections on Pipelines
}

\author{
Emiliia Iakovleva ${ }^{1, *(\mathbb{D},}$, Margarita Belova ${ }^{2}$ and Amilcar Soares $^{3}$ \\ 1 General Electrical Engineering Department, Saint Petersburg Mining University, 2, 21st Line, \\ 199106 St Petersburg, Russia \\ 2 Low-Current Networks Department, Saint Petersburg Mining University, 2, 21st Line, \\ 199106 St Petersburg, Russia; ri.parkhimchik@gmail.com \\ 3 Instituto Superior Técnico, Universidade de Lisboa, Av. Rovisco Pais, 1049-001 Lisboa, Portugal; \\ asoares@tecnico.ulisboa.pt \\ * Correspondence: yakovleva_ev@pers.spmi.ru; Tel.: +7-921-375-4619
}

\section{check for}

updates

Citation: Iakovleva, E.; Belova, M.; Soares, A. Allocation of Potentially Environmentally Hazardous Sections on Pipelines. Geosciences 2021, 11, 3. https://dx.doi.org/10.3390/ geosciences 11010003

Received: 30 November 2020 Accepted: 22 December 2020 Published: 24 December 2020

Publisher's Note: MDPI stays neutral with regard to jurisdictional claims in published maps and institutional affiliations.

Copyright: () 2020 by the authors. Licensee MDPI, Basel, Switzerland. This article is an open access article distributed under the terms and conditions of the Creative Commons Attribution (CC BY) license (https: / / creativecommons.org/ licenses/by/4.0/).

\begin{abstract}
The paper presents an analysis of the method of recording the magnetic component of the Earth's natural pulse electromagnetic field in an urban environment. This method of recording has already proved itself to be a method that allocates the stressed sections of rock mass at mining and, therefore, the authors consider it effective for allocating active tectonic disturbances and forecasting accidents at underground utilities, which will help reduce the potential environmental hazard of these objects.
\end{abstract}

Keywords: earth's natural pulse electromagnetic field; stress strain state of rock mass; magnetic field strength; magnetic induction; pipeline; measurement; accident; civil communication

\section{Introduction}

Pipelines play a significant role in the life of a modern person. They are used for the transport of oil and gas, drain sewage, supplying water and other purposes. Nowadays, this type of transportation is actively developing, and its total extensiveness is growing. However, pipelines are also a cause of environmental hazards. The consequences of pipeline accidents are diverse, but the main ones are pollution of the environmental components and decrease of biological productivity.

In cities, the largest number of pipeline accidents occur in sewerage and heating systems. These accidents directly affect the life and health of the population. Accidents in sewer networks can lead to the ingress of wastewater into the groundwater, contamination of the area adjacent to the accident site, favorable conditions for the development of pathogenic bacteria, and, as a result, epidemics.

In St. Petersburg, the situation is complicated by the proximity of the Gulf of Finland and the need to ensure a positive environmental situation in the Baltic Sea in accordance with the requirements of the Helsinki Commission. One of the causes of pipeline accidents is the stress-strain state of rock mass, wherein the generation of pulsed electromagnetic radiation occurs. The immediate causes of accidents are movements along faults edges. The possibility of such movements is described by the "active" characteristic. The direction of movement of the fault edges can be either vertical, horizontal, or combined. Vertical movements break the pipe, and horizontal movements stretch or compress it. Both scenarios lead to the destruction of the pipeline material.

The method considered in this article is based on the fact that movement along the edges of faults creates a mechanoelectrical effect of accumulation of electric charges, and then relaxation of charges in the form of pulsed spark discharges that create pulsed electromagnetic radiation in the rock mass [1].

A geodynamic fault, in the general case, is represented in the form of tectonically stressed subsoil and land surface areas, having a tendency towards dynamics [2]. Within these areas, 
the risk of natural or man-made transportation and environmental accidents increases [3-6]. Small-amplitude movements along faults can result in discontinuity in residential engineering structures, accidents in heat distribution networks and water discharge systems, gas and oil pipelines, as well as in tunnels [7]. Currently, the issue of geodynamic activity at mining facilities and related accidents at mine workings is a subject of intensive study [8-11].

Various scientific schools are engaged in researching active faults. Particular attention in this area is paid to predicting dangerous geodynamic processes in the mining industry and geodynamic risks. A group of Russian scientists have achieved significant results in this area [12-15], as well as members of the scientific school of China [16,17] and others. The obtained results can also be useful for engineering facilities that are not included in the field of mining $[18,19]$.

In urban environments, underground utilities are particularly prone to being affected by active faults as they are linear-type facilities of significant length, with high chances of crossing underground water in the city territory fault areas. These facilities are designed with a lower margin of safety than residential buildings, industrial structures and underground tunnels. Accidents involving utilities result in significant costs of repair, restoration of the territory, modernization of the infrastructure, and, inter alia, cause significant inconvenience to the population. Hot water outbursts are hazardous to human life and health. Finally, they may negatively affect the operation of city transportation [20-22].

In addition to timely diagnostics of pipeline faults, it is necessary to conduct timely hydrogeological monitoring of underground water in cities since, if there are breaches in urban communications, ground water is subject to negative impacts. A study of the geoecological state of underground water in the city territory was carried out by a team of young scientists, whose research results were presented in a series of works [23-26]. The impact of microbial activity in the underground space including metro tunnels, utility networks, deep mines, tailing dumps, infrastructure with shallow and deep foundations was studied [27].

In 2018, more than 5000 accidents involving urban heat distribution networks occurred in St. Petersburg. In 2019, in St. Petersburg, there were five major accidents in the main central heating system, and, during the winter heating season, accidents on pipelines occur on a regular basis. In February 2019, hot water pipes broke in the Kalininsky and Frunzensky districts of the city. Over the repair period, which lasted more than a day, 677 and 32 buildings, in the two districts, including schools and healthcare facilities, were disconnected from the heating system. Healthcare facilities were heated via mobile heating systems, some houses were switched to a reserve heat supply network, some houses were left without hot water supply until the elimination of the consequences of the accident. In March 2019, 280 buildings were disconnected in the Kolpinsky district, which makes nearly a half of all residential buildings in the area. Moreover, as a rule, such accidents may have tragic consequences. In the spring of 2019, a hot water pipe broke in the Krasnoselsky district of the city, as a result of which one man received thermal burns of moderate severity, and one woman received lethal thermal burns. Moreover, more than 20,000 people were left without hot water supply. At the end of September 2018, in the same district, there was a rupture of the main pipeline with the formation of a failure. As a result of the accident, two people received lethal thermal burns, and damage was caused to the property of some citizens.

To reduce the number of accidents, municipal heat supply services perform replacement of old utilities and conduct timely diagnostics of highways [28-31]. The authors of this paper assume that the application of the method of measuring the magnetic component of the Earth's natural pulse electromagnetic field is expedient for allocating emergency sections induced by the stress-strain state of the soils surrounding the pipeline.

The study of tectonic disturbance activity began in the 1950s, but the concept of "active fault" was introduced in the 1970s [32-36]. At the same time, despite the similarity of the definitions of "active fault" proposed by scientists of multiple countries, 
a single definition still does not exist. According to [32], which made an attempt to generalize all available definitions, an active fault is a disjunctive tectonic disturbance of geological bodies in the relief or in subsoil, characterized by evidence of directional movement of blocks being separated by tectonic disturbance during the past hundreds of thousands of years at an average speed of at least hundredths of a mm per year. However, the disturbance activity duration is not a category that is convenient to apply practically, therefore it is expedient to proceed with definite quantitative values that can be recorded. The magnetic component (MC) of the Earth's natural pulse electromagnetic field (ENPEMF) can be considered to be one of such values. It is known that the Earth's electromagnetic field is a superposition of electromagnetic fields of different nature [37]. The resultant electromagnetic field is alternating and has a pulsed nature. The ENPEMF has the background values of the concentration of charges in rock mass, the magnitudes of strength of the electric $\mathrm{E}$ and magnetic $\mathrm{H}$ fields, magnetic induction B and magnetic flux $\Phi$. The background value depends on the properties of the surrounding space- the structure of rock mass, dynamoelectric phenomena occurring in rock mass, microseismic motion, manmade load, etc. Further, the ENPEMF is characterized by the presence of pulsed signals from remote sources, such as atmospherics and deep lithospheric processes $[10,38]$. Such pulsed signals are characterized by equal peak value of the signal at each point; therefore, they are not recorded during measurements, but increase the background value. In addition, it is worth noting that the background value is also affected by various manmade factors. However, since the operating frequency of manmade sources (cable power lines, operating electromechanical installations, etc.) is $50 \mathrm{~Hz}$ and the sources generate a signal harmonically varying according to the sine law, this component can be easily excluded. The method of recording the ENPEMF magnetic component consists in measuring the magnitude of the EMF induced in the receiving antenna and falling within an alternating electromagnetic field.

Earthquake prediction was one of the first fields of application for the method of recording the ENPEMF MC. This is due to the fact that a high concentration of charges is not typical for a stable equilibrium of the system; therefore, it is an earthquake precursor [39,40]. Later this method was transformed and developed in this area. For instance, the VAN method is known. The method is based on the measurement of low frequency electrical signals (SES). According to this method, SES are recorded and evaluated in different stations [41,42].

To adapt the EMF method to the conditions of underground mining, to determine the sufficient sensitivity of the method for recording seismic events of much lower energy than an earthquake, a joint research with other noncontact and contact geophysical methods was implemented. Along with others, the core disking method was widely used as the most studied one [43]. Further, specialists of the Mining University conducted work on the comparison of EMF data and acoustic emission [44,45].

According to the results of multiyear research aimed at predicting a rock-bump hazard at ore and nonore deposits, it was revealed that the indicator of the modern geodynamic activity of faults is the variability of the ENPEMF characteristics in space and time compared to the adjacent areas. Therefore, the team of authors proposed to adapt the method of measuring the ENPEMF MC for the urban environment. For this purpose, a number of streets have been selected along which underground utilities are laid and where accidents have been recently registered, namely, pipeline breaks, ground collapses, and associated liquid spills.

\section{Materials and Methods}

To analyze the efficiency of the ENPEMF MC measurements, carried out to identify active faults and detect hazardous areas, the following actions were carried out:

- Accident sampling over underground utilities;

- Comparison of the sampling obtained with the ENPEMF MC measurement results;

- Comparison of the ENPEMF MC measurement results with the information on tectonic disturbances from a 1:25,000 scaled map, compiled by E.K. Melnikov, according to the 
order by St. Petersburg Government Committee for Urban Planning and Architecture, in 1994.

However, it is worth noting that not all faults plotted on the map [46] are active and pose a threat to engineering facilities, subsequently, a simple comparison between accidents and the map will not ensure a reliable result. Moreover, information on accidents at underground utilities is not structured to date. Therefore, this study involves the analysis of both scientific and technical sources as well as mass media news feeds.

To conduct the study, a receiving antenna in the form of an inductance coil with a constant ferromagnetic core was used. Ferromagnetic materials were used to expand the measurement limits of the recorded signals since the induced EMF ranges from several $\mu \mathrm{V}$ to tens of $\mathrm{mV}$. An alternating voltage voltmeter served as a recording device.

The method of recording the ENPEMF MC included recording the magnitude of the EMF induced in the receiving antenna falling within the alternating electromagnetic field in accordance with the law of electromagnetic induction. A rod of the antenna had the following characteristics: core material- $\mathrm{M} 400 \mathrm{HH}$, according to the Russian material classification; initial magnetic permeability $-400 \mathrm{H} / \mathrm{m}$; rod diameter $-10 \mathrm{~mm}$; rod length$200 \mathrm{~mm}$; winding $-180 \mathrm{~mm}$; the diameter of the copper wire was $0.1 \mathrm{~mm}$; the number of turns was about 3000 . Constant sensitivity was confirmed in the frequency range from 1 to $18 \mathrm{kHz}$. The APPA-109N device was used as a recorder. Measurements in three directions of the antenna were carried out along the streets with a $5 \mathrm{~m}$ measurement pitch. The holding time at each pitch was $10 \mathrm{~s}$.

Subsequently, the studied areas were analyzed geologically. The upper layers of a typical geological record in this area of the city are Quaternary deposits, which are interbedded sandy-clay soils. The thickness of the layer of Quaternary deposits is not consistent and varies from 30 to $40 \mathrm{~m}$ in the studied area. There are peat interlayers in the upper part of the Quaternary deposits. Quaternary sediments are everywhere covered by technogenic soils from above, the thickness of which is less than $5 \mathrm{~m}$. The depth of the groundwater level is $2 \mathrm{~m}$. The bedding rocks are the Upper Vendian Verkhnekotlinsky clays. They are dense, dry, hard clays, with interbedded sandstone. The upper part is more humid; the lower part is drier and where the sandstones may appear. The crystalline basement lies at a depth of about $200 \mathrm{~m}$ and consists of granites, quartzites, gneisses $[47,48]$.

Tectonic faults occur in the sedimentary cover rocks and are prolonged by basement faults. The average width of the investigated faults is $80-100 \mathrm{~m}$. Tectonic faults have no outlet in the series of the Quaternary deposits and are traced only by indirect indicators. Thus, for this study, it is necessary to take into account that the signal is generated in bedrocks and basement rocks and passes through the series of loose sediments.

To establish the validity of the study, it is necessary to determine the possibility to register on the surface a signal from a source located at the average depth of the base of the Quaternary sediments (about $35 \mathrm{~m}$ ). To that end, it is necessary to take into account the values of the electrical and magnetic parameters of soils. Table 1 shows the averaged values of the electrical and magnetic parameters of soils typical for the investigated area for a frequency of $1 \mathrm{kHz}$.

As can be seen from the table, soil parameters cannot obstruct the passage of a pulsed electromagnetic field generated by active tectonic faults. The pulse frequency varies from $10^{3}$ to $10^{5} \mathrm{~Hz}$, so the length of the electromagnetic wave will be hundreds of times longer than the distance to the receiving device.

According to Faraday's law, the magnitude of the EMF occurring in a coil with a constant core is equal to the rate of change in magnetic flux through a surface limited by the coil loop:

$$
\mathrm{e}=-\frac{d \Phi}{d t}
$$


Table 1. Average values of electric and magnetic parameters of soils characteristic of the studied area for the frequency of $1 \mathrm{kHz}$.

\begin{tabular}{|c|c|c|c|c|c|}
\hline & $\begin{array}{c}\text { Type of } \\
\text { the Deposit }\end{array}$ & Name & Permittivity, F/m & $\begin{array}{c}\text { Electrical } \\
\text { Resistivity, Om/m }\end{array}$ & $\begin{array}{c}\text { Magnetic Susceptibility, } \\
\text { Unit Measure SI } \\
\text { System } 10^{-5}\end{array}$ \\
\hline 1 & Quaternary & $\begin{array}{l}\text { Sea-lake sand and } \\
\text { sabulous clay }\end{array}$ & $15-20$ & 10-100 & $20-2800$ \\
\hline 2 & deposits & $\begin{array}{c}\text { Glaciolacustrine and } \\
\text { banded clay-bearing soil } \\
\text { with sand and sabulous } \\
\text { clay lens }\end{array}$ & $8-20$ & 100-1000 & $50-25,000$ \\
\hline 3 & & $\begin{array}{l}\text { Clay-bearing soil of the } \\
\text { Ostashkovskaya till with } \\
\text { inclusions of alluvium } \\
\text { and ratchel }\end{array}$ & $4.5-10$ & $1000-10,000$ & $10-3000$ \\
\hline 4 & Bedding rock & $\begin{array}{l}\text { Upper Vendian } \\
\text { Verkhnekotlinsky clays with } \\
\text { interbedded sandstone }\end{array}$ & $4.5-40$ & $1000-1,000,000$ & $50-5000$ \\
\hline
\end{tabular}

The magnetic flux is proportional to the magnitude of the magnetic induction vector $\mathrm{B}$, the area of the limited loop $S$ and the cosine of the angle between the magnetic induction vector $B$ and the normal to the loop plane:

$$
\Phi=B S \cos \alpha
$$

As is known, the magnetic induction vector $B$ is directly proportional to the magneticfield vector $H$ :

$$
\vec{B}=\mu_{0} \mu \vec{H},
$$

where $\mu_{0}$ is the absolute magnetic permeability of the vacuum, $\mu$ is the relative magnetic permeability of the medium.

According to the dependences depicted above, the magnitude of the EMF E, typical for the studied section with a length of several hundred meters, will also have a background value since the nature of the change in magnetic flux will be constant in the absence of geodynamic activity. Nonetheless, if stress-strain states occur in rock mass, the recorded signal acquires a step-like variable shape. The amplitudes of such anomalous values of $\mathrm{E}$ can exceed the background value by many times and have both positive and negative values.

The occurrence of anomalous values is due to the occurrence of an elastic wave formed under the action of deforming forces that arise with the change in mechanical and hydrogeological properties, the stress state of the soil massif, which also comes with increased intensity of corrosion activity. The deforming forces cause the redistribution of charges at the edges of geological faults, and, as is known, the redistribution of charges is accompanied by their movement, which results in induction of short-term electromagnetic fields of greater intensity.

The value of EMF before the occurrence of stress-strain state is a variable magnitude of a pulsed nature, which has a background value of $E_{F}(t)$. The occurrence of stress-strain state in massif results in a change in $E_{F}$ by the value of $\Delta E$. Therefore, the induced EMF $E_{F}^{\prime}$ in the disturbed massif will be equal to:

$$
E_{F}^{\prime}=E_{F}(t) \pm \Delta E(t),
$$

The value of $\Delta E$ is the anomaly amplitude and can take both positive and negative values. Therefore, it can increase or decrease the background value of $E_{F}$. This is explained by the principle of superposition. The increase in the background value is due to the enhancement of electromagnetic emission, and, thereby, the electromagnetic field enhancement, i.e., increase in vectors of electric and magnetic fields, takes place. The enhancement is due to the accordant direction of the background field and the field induced by stress-strain state. 
At a negative value of the amplitude, the pulse electromagnetic field, occurring under deformation, is directed opposite to the background field.

Thus, according to this method, not only the excess over the background value, but also the minimum values of the EMF, should be taken into account.

\section{Results}

The averaged value of amplitudes that exceed significance levels is deemed to be an informative indicator of electromagnetic radiation of a geological nature. In this study, the criterion for allocating abnormal areas is a change in the indicator by more than $20 \%$, regardless of its sign.

Profiling was performed under the mode of discrete measurements at a pitch of $20 \mathrm{~m}$ along the surface. The exposure time was $10 \mathrm{~s}$ at a point. Signals were recorded at three orientations of the antenna magnetic moment: one vertical and two horizontal—forward along the profile and across the profile.

Figure 1 illustrates some of the results of the study. It can be seen from the figures that discontinuous faults are clearly recorded on the profiles of the ENPEMF MC, wherein most accidents are confined to the areas of these faults. In this figure, the diagram of the vertical component $A_{Z}$ is taken as representative. As can be seen from the diagram, in the measurement areas from 0 to $30 \mathrm{~m}$, from 460 to $500 \mathrm{~m}$, from 790 to $820 \mathrm{~m}$ and from 1080 to $1110 \mathrm{~m}$, the parameters of $\Delta E$ exceed the background value of $E_{F}$ by more than $20 \%$. These areas coincide with the sites of accidents at underground utilities.

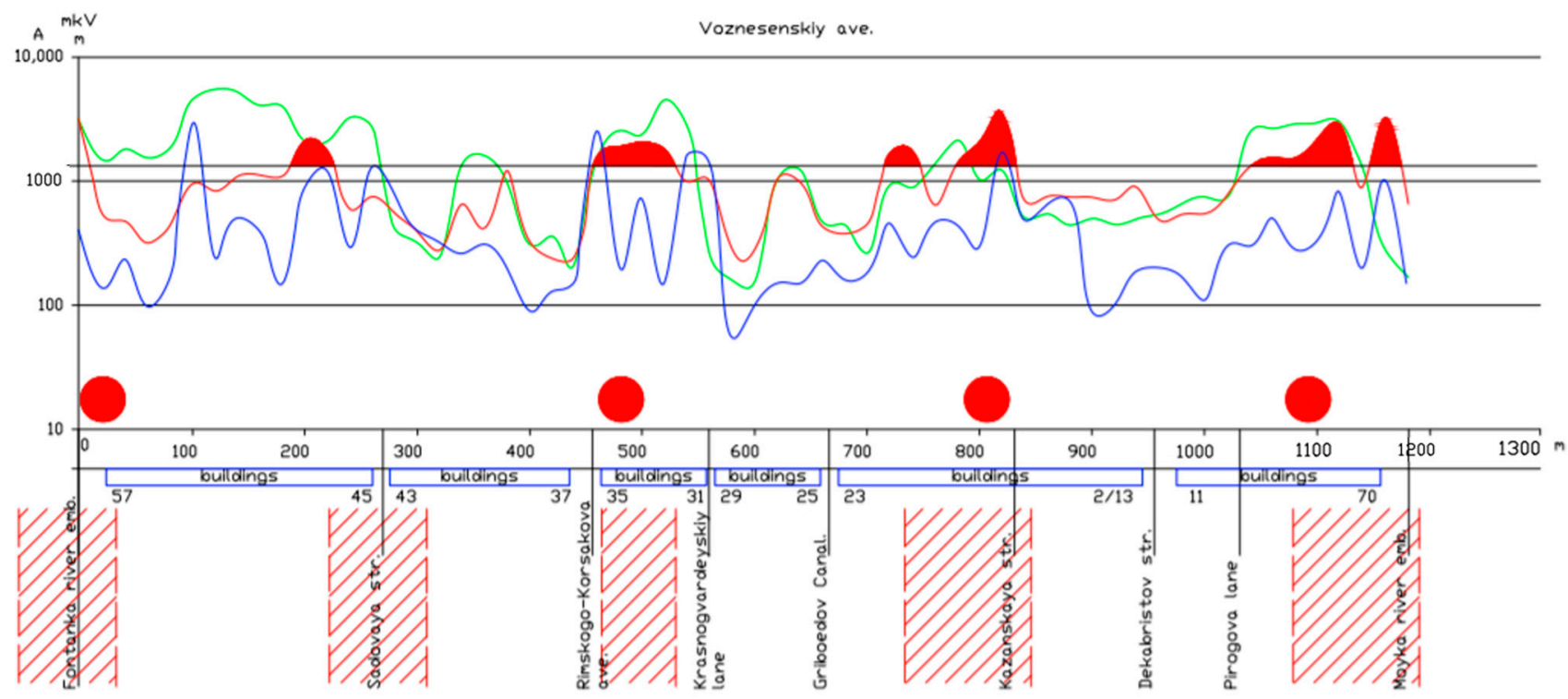

Figure 1. The results of the measurement of the magnetic component (MC) of the Earth's natural pulse electromagnetic field (ENPEMF) along Voznesenskiy Avenue, Saint Petersburg, Russian Federation.

The results of the study, presented in Figure 2, also demonstrate the convergence of the location of the anomalies by AZ and the sites of accidents on the pipelines. However, at $450 \mathrm{~m}$, a fluctuation in the AEMF MC curve, which coincides with the place of the pipeline break but does not coincide with any disturbance shown on the map, is observed [30]. This is probably due to the fact that either the disturbance actually exists but is not plotted on the map, and, therefore, adjustments are required, or this disturbance was not active during the map compilation period but during the research period the movement began again. It is also possible that there is a low-ranked disturbance in this section, wherein high voltage is concentrated, and at the time of the massif unloading (discontinuous fault expansion), an accident occurred. 


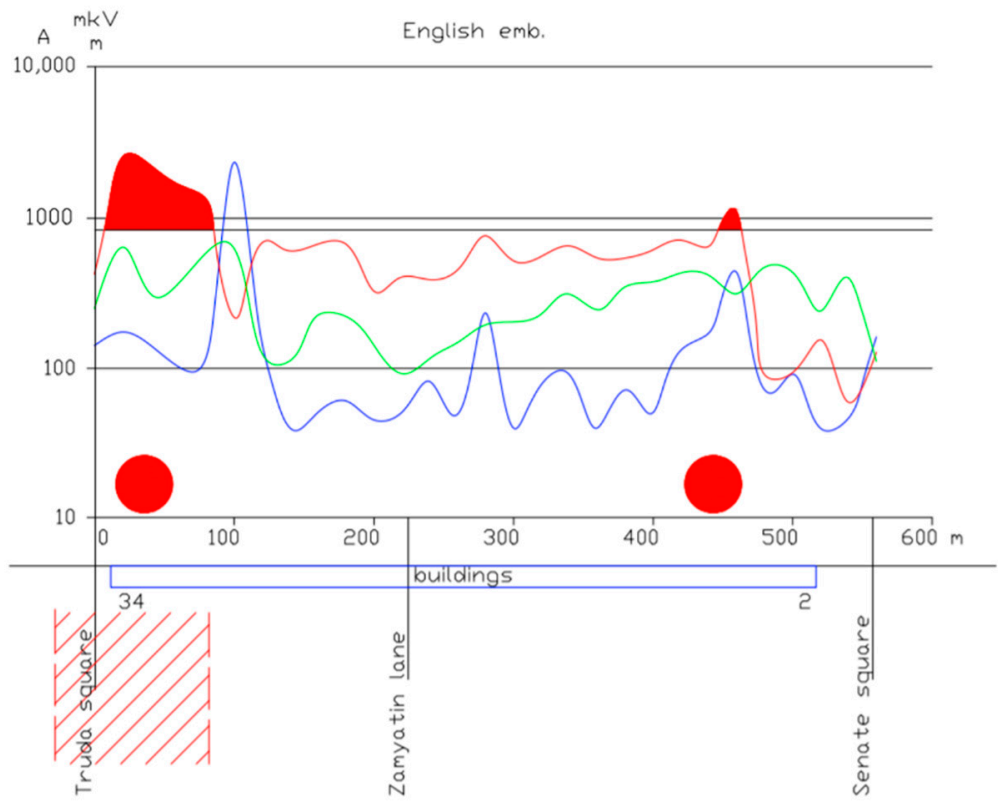

Figure 2. The results of the measurement of the ENPEMF MC along the English Embankment, Saint Petersburg, Russian Federation.

Figure 3 illustrates the results, confirming the conclusions made earlier. The diagram also shows a slight fluctuation at the point of $170 \mathrm{~m}$, which coincides with the accident site but virtually does not overcome the threshold of $20 \%$ of the background. For this section, the assumptions concerning the anomaly at $450 \mathrm{~m}$ in the previous curve are probably also true. A discontinuous fault in the area of the Moyka river embankment was not mapped according to the accepted method due to the insufficient profile length in this area.

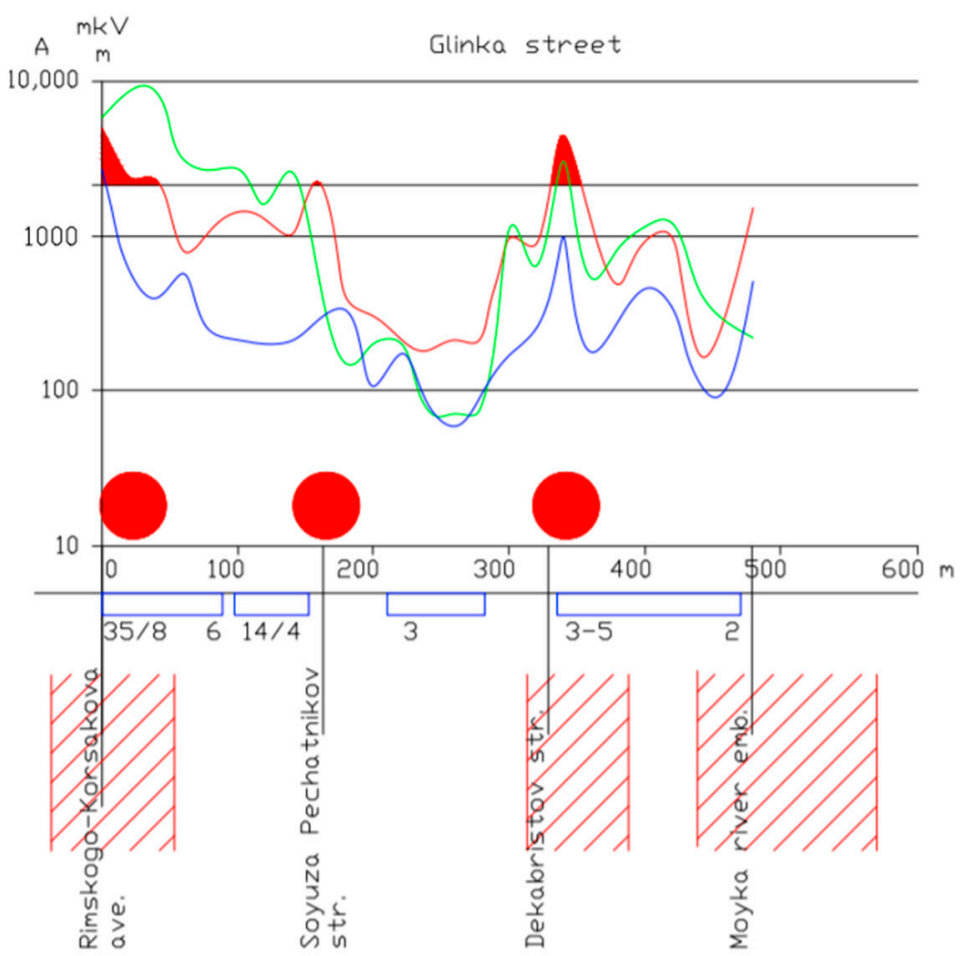

Figure 3. The results of the measurement of the ENPEMF MC along Glinka Street, Saint Petersburg, Russian Federation.

Designations, used in Figures 1-3, are given in Table 2. 
Table 2. Designations to figures.

Note
$\begin{gathered}\text { Vertical component of } \\ \text { the ENPEMF MC Arizontal } \\ \text { component (along the } \\ \text { profile) Ax } \\ \text { Horizontal } \\ \text { component } \\ \text { (perpendicular to the } \\ \text { profile) Ay }\end{gathered}$

Thus, the length of the zones affected by geodynamically active faults (GAF) amounted to about $20 \%$ of the profile total length. Meanwhile, the locations of 41 out of 51 known accidents coincided with the zones affected by GAF, which also means that the ratio of the number of accidents per running meter within zones of GAF to the number of accidents beyond their bounds made 17.3. The data obtained indicate that the number of accidents at underground utilities is much greater within the zones affected by GAF than beyond their bounds, however, to conclude more precisely, it is necessary to perform further collection of statistical data on accidents. Table 3 summarizes the results of the study.

Table 3. Designations to figures.

\begin{tabular}{|c|c|}
\hline Characteristics & Value \\
\hline $\begin{array}{l}\text { The total length of the electrical survey profile, with recording of the AEMF } \\
\text { magnetic component, in } \mathrm{km}\end{array}$ & 6.38 \\
\hline $\begin{array}{l}\text { The total length of the zones affected by GAF, allocated by the sum of geological } \\
\text { data, in running km }\end{array}$ & 1.22 \\
\hline The total length of internal fault-blocks in running $\mathrm{km}$ & 5.16 \\
\hline $\begin{array}{c}\text { The total number of accidents at underground utilities of the } \\
\text { water supply system }\end{array}$ & 51 \\
\hline $\begin{array}{l}\text { The number of accidents at underground utilities of the water supply system } \\
\text { within the zones affected by GAF }\end{array}$ & 41 \\
\hline $\begin{array}{c}\text { The number of accidents at underground utilities of the water supply system } \\
\text { beyond the bounds of GAF }\end{array}$ & 10 \\
\hline $\begin{array}{l}\text { The number of accidents at underground utilities of the water supply system } \\
\text { within the zones affected by GAF per running } \mathrm{km}\end{array}$ & 33.61 \\
\hline $\begin{array}{l}\text { The number of accidents at the underground utilities of the water supply system } \\
\text { beyond the bounds of GAF per running km }\end{array}$ & 1.94 \\
\hline $\begin{array}{c}\text { The ratio of the number of accidents within the zones affected by GAF to the } \\
\text { number of accidents beyond their bounds }\end{array}$ & 17.34 \\
\hline
\end{tabular}

\section{Discussion}

The method of recording the ENPEMF MC in an urban environment has shown good convergence of the recorded anomalies and known active faults, to which accidents at urban utilities, in particular in lines of water supply and water discharge systems, are confined. Nonetheless, not all active faults plotted on the map [46], confirming the geodynamically active pattern according to data of morphometric and lineament analyzes, are recorded within the field, which is due to the high ratio of the thickness of tectonic disturbances and the overlying strata-sediments. In addition, the result obtained indirectly indicates a variable degree of activity, namely, the concentration of natural stress fields within separate geodynamic blocks, bound by the disturbances under consideration. It is worth noting that 
the complexity associated with allocating low-ranked disturbances, with a high probability, is not substantiated in terms of the method accuracy with respect to the allocation of potential emergency sections on pipelines since, as a rule, in diagrams, such disturbances are presented in the form of a single fluctuation zone, and to implement the most reliable allocation thereof, the existing measurement techniques should be substantially altered.

\section{Conclusions}

Hereby, the field studies, which were conducted on more than $6 \mathrm{~km}$ of streets in an urban environment, have shown a high efficiency of the method for identifying potentially dangerous areas on underground utilities. The obtained data also demonstrate that the vertical component $\mathrm{Az}$ is the most significant one, since it has the highest convergence of data, and it is also the least susceptible to manmade interference.

Eighty percent of accidents which took place in the considered areas occurred in the GAF zones, and all the accidents correlate in the graphs with fluctuations of more than $20 \%$. Two accidents that are not spatially related to the known GAF zones are reflected in the graphs by anomalies of a smaller order.

It is also worth noting that the main advantage of the method in comparison with other geophysical methods used for solving such problems is the ability to perform measurements at any time of the year with few staff and high productivity and also that there is no need for grounding.

The authors consider the possibility of further developing the studied method to implement a monitoring system at underground utilities of water supply and water discharge systems based on the tested instrumental base. The use of this method at the stage of predesign and design surveys in the future, with further consideration of hazardous zones allocation during installation of the utility system facilities, will make it possible to reduce the accident rate at underground utilities of water supply and water discharge systems. Moreover, the use of this method in combination with operating monitoring systems will significantly reduce the time of allocating an emergency section, and allow the determining of the causes of its occurrence. This will reduce the time for performing repair work and allow entering corrections in the design solution with respect to this zone due to applying compensatory measures. As a result, an increase of living standards of the population in the urban environment and a decline if the negative impacts on the environment, the likelihood of injury and the death of people and animals are expected.

Author Contributions: Conceptualization, E.I., M.B. and A.S.; methodology, E.I.; validation, E.I. and M.B.; investigation, E.I. and M.B.; writing—original draft preparation, E.I. and M.B.; writing-E.I., M.B. and A.S.; visualization, E.I. and M.B.; All authors have read and agreed to the published version of the manuscript.

Funding: This research received no external funding.

Institutional Review Board Statement: Not applicable.

Informed Consent Statement: Not applicable.

Data Availability Statement: Data available on request.

Acknowledgments: The team of authors acknowledges anonymous reviewers for their feedback, which for sure improved the clarity and quality of this paper.

Conflicts of Interest: The authors declare no conflict of interest.

\section{References}

1. Bezrodny, K.P.; Basov, A.D.; Romanevich, K.V. Control of the stress-strain state of the rock mass during tunnel construction using natural electromagnetic radiation method. Izv. Tula State Univ. Earth Sci. 2011, 1, 227-234. (In Russian)

2. Turchaninov, I.A.; Markov, G.A. Abnormally high stress state of rock massifs and its accounting in underground mining. In The Physical Conditions and the Development of the Technology of Mining Production; Nauka: Leningrad, Russia, 1973; pp. 34-42. (In Russian) 
3. Rasskazov, I.Y.; Tsirel, S.V.; Rozanov, A.O.; Tereshkin, A.A.; Gladyr', A.V. Application of acoustic measurement data to characterize initiation and development of disintegration focus in a rock mass. J. Min. Sci. 2017, 53, 224-231. [CrossRef]

4. Norvatov, Y.A.; Petrova, I.B.; Kotlov, S.N. Hydroecological conditions for the opencast mining of the grib diamond deposit. Water Resour. 2012, 39, 798-801. [CrossRef]

5. Haji, T.A.; Moumni, Y.; Msaddek, M.H. Fault-style analysis and seismic interpretation: Implications for the structural issues of the South-eastern Atlas in Tunisia. J. Afr. Earth Sci. 2020, 172, 103962. [CrossRef]

6. Abreha, D.A. Analysing Public Transport Performance Using Efficiency Measures and Spatial Analysis; The Case Study of Addis Ababa, Ethiopia. Masters' Thesis, International Institute for Geo-Information Science and Earth Observation, Enschede, The Netherlands, 2007.

7. Litvinenko, V.S.; Kozlov, A.V.; Stepanov, V.A. Hydrocarbon potential of the Ural-African transcontinental oil and gas belt. J. Pet. Explor. Prod. Technol. 2017, 7, 1-9. [CrossRef]

8. Kholodilov, A.N.; Gospodarikov, A.P. Modeling Seismic Vibrations under Massive Blasting in Underground Mines. J. Min. Sci. 2020, 56, 29-35. [CrossRef]

9. Lebedev, M.O.; Romanevich, K.V. Engineering and geophysical research in reconstruction of underground structures. Min. Inf. Anal. Bull. 2019, 2019, 97-110. [CrossRef]

10. Mulev, S.N.; Starnikov, V.N.; Romanevich, O.A. The current stage of development of the geophysical method for recording natural electromag neticra diation (EEMI-NER). Ugol 2019, 10, 6-14. [CrossRef]

11. Ezersky, M.; Eppelbaum, L. Geophysical Monitoring of Underground Constructions and its Theoretical Basis. Int. J. Georesour. Environ. 2017, 3, 56-72. [CrossRef]

12. Shabarov, A.; Tsirel, S. Geodynamic safety of subsurface management. Geomech. Geodyn. Rock Masses 2018, 1, 105-120.

13. Tsirel', S.V.; Pavlovich, A.A.; Melnikov, N.Y.; Zuev, B.Y. Physical Modeling of Deformation Processes in Pit Slope with Steep Bedding. J. Min. Sci. 2019, 55, 364-370. [CrossRef]

14. Morozov, K.; Shabarov, A.; Kuranov, A.; Belyakov, N.; Zuyev, B.; Vlasenko, D.; Demekhin, D.; Bakhtin, E. Geodynamic monitoring and its maintenance using modeling by numerical and similar materials methods. In Proceedings of the 1st International Scientific Conference on Problems in Geomechanics of Highly Compressed Rock and Rock Massifs, GHCRRM 2019, Vladivostok, Russia, 15 July 2019.

15. Karasev, M.A.; Bouslova, M.A.; Vilner, M.A.; Nguyen, T.T. Method for predicting the stress-strain state of the vertical shaft lining at the drift landing section in saliferous rocks. J. Min. Inst. 2019, 240, 628-637. [CrossRef]

16. Zhu, Z.; Zhang, H.; Han, J.; Lv, Y. A Risk Assessment Method for Rockburst Based on Geodynamic Environment. Shock Vib. 2018, 2018, 2586842. [CrossRef]

17. Han, J.; Zhang, H.-W.; Song, W.-H.; Li, S.; Lan, T.-W. Coal and gas outburst mechanism and risk analysis of tectonic concave. Meitan Xuebao/J. China Coal Soc. 2011, 36, 108-113.

18. Zuev, B.Y.; Zubov, V.P.; Fedorov, A.S. Application prospects for models of equivalent materials in studies of geomechanical processes in underground mining of solid minerals. Eurasian Min. 2019, 1, 8-12. [CrossRef]

19. Marschalko, M.; Yilmaz, I.; Bednárik, M.; Kubečka, K. Variations in the building site categories in the underground mining region of Doubrava (Czech Republic) for land use planning. Eng. Geol. 2011, 122, 169-178. [CrossRef]

20. Susetyaningsih, A.; Farida, I.; Zhafirah, A. Optimization of utilization pedestrian trails and green lines in the city. J. Phys. Conf. Ser. 2019, 1402, 022015. [CrossRef]

21. Ai, Q.; Yuan, Y. Rapid acquisition and identification of structural defects of metro tunnel. Sensors 2019, 19, 4278. [CrossRef]

22. Zubov, V.P.; Nikiforov, A.V. Features of development of superimposed coal seams in zones of disjunctive geological disturbances. Int. J. Appl. Eng. Res. 2017, 12, 765-768.

23. Protosenya, A.G.; Lebedev, M.O.; Karasev, M.A.; Belyakov, N.A. Geomechanics of low-subsidence construction during the development of underground space in large cities and megalopolises. Int. J. Mech. Prod. Eng. Res. Dev. 2019, 9, 1005-1014.

24. Lange, I.Y.; Lebedeva, Y.A.; Kotiukov, P.V. A study of water permeability of coal ash and slag to assess the possibility of their use as road pavement layers. Int. J. Eng. Res. Technol. 2020, 13, 374-378. [CrossRef]

25. Lebedeva, Y.; Kotiukov, P.; Lange, I. Study of the geo-ecological state of groundwater of metropolitan areas under the conditions of intensive contamination thereof. J. Ecol. Eng. 2020, 21, 157-165. [CrossRef]

26. Dashko, R.E.; Lebedeva, Y.A. Improving Approaches to Estimating Hydrogeological Investigations as a Part of Engineering Survey in Megacities: Case Study of St. Petersburg. Water Resour. 2017, 44, 875-885. [CrossRef]

27. Dashko, R.; Shidlovskaya, A. Impact of microbial activity on soil properties. Can. Geotech. J. 2016, 53, 1386-1397. [CrossRef]

28. Eboli, L.; Mazzulla, G. A stated preference experiment for measuring service quality in public transport. Transp. Plan. Technol. 2008, 31, 509-523. [CrossRef]

29. Eboli, L.; Mazzulla, G. Willingness-to-pay of public transport users for improvement in service quality. Eur. Transp. Trasp. Eur. 2008, 38, 107-118.

30. Hanrahan, R.B.; Layde, P.M.; Zhu, S.; Guse, C.E.; Hargarten, S.W. The association of driver age with traffic injury severity in Wisconsin. Traffic Inj. Prev. 2009, 10, 361-367. [CrossRef]

31. Badami, M.G.; Haider, M. An analysis of public bus transit performance in Indian cities. Transp. Res. Part A: Policy Pract. 2007, 41, 961-981. [CrossRef]

32. Nikonov, A.A. Active faults: Definition and allocation problems. Geoecology 1995, 4, 16-27. (In Russian) 
33. Bolt, A.B.; Scott, R.W.; Horn, W.L.; MacDonald, G.A. Geological Elements: Earthquakes, Tsunamis, Volcanic Eruptions, Avalanches, Landslides, Floods; Mir: Moscow, Russia, 1978; p. 444.

34. Asada, T. Earthquake Prediction Techniques: Their Application in Japan; Nedra: Moscow, Russia, 1984; p. 312. (In Russian)

35. Ufimtsev, G.F.; Onukhov, F.S.; Timofeev, D.A. Terminology of Structural Geomorphology and Neotectonics; Nedra: Moscow, Russia, 1979; p. 256.

36. Research Group for Active Faults. Active faults in and around Japan: The distribution and the degree if activity. J. Nat. Disas. Sci. 1980, 2, 61-99.

37. Zhdanov, M.S. Geophysical Electromagnetic Theory and Methods; Elsevier: Amsterdam, The Netherlands, 2012 ; p. 680.

38. Lyu, C.; Pedersen, H.A.; Paul, A.; Zhao, L.; Solarino, S. Shear wave velocities in the upper mantle of the Western Alps: New constraints using array analysis of seismic surface waves. Geophysics. J. Int. 2017, 210, 321-331. [CrossRef]

39. Wen, Y.; Xu, C.; Liu, Y.; Jiang, G. Deformation and Source Parameters of the 2015 Mw 6.5 Earthquake in Pishan, Western China, from Sentinel-1A and ALOS-2 Data. Remote Sens. 2016, 8, 134. [CrossRef]

40. Zubaidah, T.; Kanata, B.; Irmawati, B.; Ramadhani, C. Comprehensive Geomagnetic Signal Processing for Successful Earthquake Prediction. In Proceedings of the 13th Quality in Research (QiR) 2013, Yogyakarta, Indonesia, 25-28 June 2013.

41. Sarlis, N.V.; Skordas, E.S. Study in natural time of geoelectric field and seismicity changes preceding theMw6.8 earthquake on 25 October 2018 in Greece. Entropy 2018, 20, 882. [CrossRef] [PubMed]

42. Varotsos, P.A.; Skordas, E.S.; Sarlis, N.V. Fluctuations of the entropy change under time reversal: Further investigations on identifying the occurrence time of an impending major earthquake. EPL 2020, 130, 29001. [CrossRef]

43. Zubov, V.P.; Nikiforov, A.V.; Kovalsky, E.R. Influence of geological faults on planning mining operations in contiguous seams. Ecol. Environ. Conserv. 2017, 23, 1176-1180.

44. Belova, M.; Iakovleva, E.; Popov, A.; Idiyatullin, M. Localization of potentially dangerous geodynamic zones in underground mines. Rock Mechanics for Natural Resources and Infrastructure Development. In Proceedings of the 14th International Congress on Rock Mechanics and Rock Engineering, ISRM, Foz Do Iguassu, Brazil, 13-18 September 2019; pp. 1441-1447.

45. Guzev, M.A.; Rasskazov, I.Y.; Tsitsiashvili, G.S. Algorithm of Potentially Burst-hazard Zones Dynamics Representation in Massif of Rocks by Results of Seismic-acoustic Monitoring. Procedia Eng. 2017, 191, 36-42. [CrossRef]

46. Trifonov, V.G. Living tectonics of Holocene. Bull. Ussr Acad. Sci. 1987, 4, 99-112.

47. Dashko, R.E.; Shidlovskaya, A.V.; Aleksandrova, O.Y.; Alekseev, I.V. Geological engineering and hydrogeological problems of substantiating the long-term stability of St. Isaac's Cathedral (St. Petersburg). J. Min. Inst. 2012, 195, 28-32. (In Russian)

48. Dashko, R.E.; Aleksandrova, O.Y.; Kotiukov, P.V.; Shidlovskaya, A.V. Special aspects of geotechnical conditions of St. Petersburg. Urban Dev. Geotech. Constr. 2011, 1, 1-47. (In Russian) 